\title{
Projected changes in diverse ecosystems from climate warming and biophysical drivers in northwest Alaska
}

\author{
Mark Torre Jorgenson • Bruce G. Marcot • \\ David K. Swanson • Janet C. Jorgenson • \\ Anthony R. DeGange
}

Received: 7 July 2014 / Accepted: 23 November 2014 / Published online: 18 January 2015

(C) The Author(s) 2014. This article is published with open access at Springerlink.com

\begin{abstract}
Climate warming affects arctic and boreal ecosystems by interacting with numerous biophysical factors across heterogeneous landscapes. To assess potential effects of warming on diverse local-scale ecosystems (ecotypes) across northwest Alaska, we compiled data on historical areal changes over the last 25-50 years. Based on historical rates of change relative to time and temperature, we developed three state-transition models to project future changes in area for 60 ecotypes involving 243 potential transitions during three 30 -year periods (ending 2040, 2070, 2100). The time model, assuming changes over the past 30 years continue at the same rate, projected a net change, or directional shift, of $6 \%$ by 2100 . The temperature model, using past rates of change relative to the past increase in regional mean annual air temperatures $\left(1{ }^{\circ} \mathrm{C} / 30\right.$ year), projected a net change of $17 \%$ in response to expected warming of 2,4 , and $6{ }^{\circ} \mathrm{C}$ at the end of the three periods. A rate-adjusted temperature model, which adjusted transition rates $( \pm 50 \%)$ based on assigned feedbacks associated with 23 biophysical drivers, estimated a net change of $13 \%$, with 33 ecotypes gaining and 23 ecotypes losing area. Major drivers included shrub and tree expansion, fire, succession, and thermokarst. Overall, projected
\end{abstract}

Electronic supplementary material The online version of this article (doi:10.1007/s10584-014-1302-1) contains supplementary material, which is available to authorized users.

M. T. Jorgenson $(\bowtie)$

Alaska Ecoscience, 2332 Cordes Way, Fairbanks, AK 99709, USA

e-mail: ecoscience@alaska.net

B. G. Marcot

USDA Forest Service, Pacific Northwest Research Station, 620 SW Main St., Suite 400, Portland, OR 97205, USA

D. K. Swanson

National Park Service, 4175 Geist Rd, Fairbanks, AK 99709, USA

J. C. Jorgenson

Arctic National Wildlife Refuge, 101 12th Ave, Room 236, Fairbanks, AK 99701, USA

A. R. DeGange

Alaska Climate Science Center, U. S. Geological Survey, 4210 University Drive, Anchorage, AK 99508, USA 
changes will be modest over the next century even though climate warming increased transition rates up to 9 fold. The strength of this state-transition modeling is that it used a large dataset of past changes to provide a comprehensive assessment of likely future changes associated with numerous drivers affecting the full diversity of ecosystems across a broad region.

\section{Introduction}

Ecosystems over large regions are highly diverse owing to gradients in environmental conditions and disturbance regimes, and they can be expected to respond differently to climate warming. In arctic and boreal biomes a wide range of atmospheric, hydrologic, geomorphic, fire, biotic, and anthropogenic drivers can affect ecological patterns and processes that raise concern for ecosystem management and subsistence resources (Chapin et al. 2006; Martin et al. 2009). To project future change in northwest Alaska from climate warming, we address the complexity of diverse ecosystems and biophysical drivers by using a state-transition modeling approach that incorporates a large number of historical observations of past rates of change.

The factors affecting ecological responses to climate change are being assessed on many fronts. Warming air temperatures have led to changing water balance (Riordan et al. 2006) and surface and subsurface hydrology (Walvoord et al. 2012). Permafrost degradation has increased (Jorgenson et al. 2006; Grosse et al. 2011), which radically reorganizes hydrologic flow paths, soil processes, and vegetation (Jorgenson et al. 2013). Compositional shifts or biomass changes in vegetation are occurring through nutrient cycling and competitive interactions among plant species (Potter et al. 2013), snow cover change (Sturm et al. 2005), herbivory (Joly et al. 2009), and thermokarst (Jorgenson et al. 2001). Increasing fire frequency and severity associated with climate warming may lead to a shift in forest composition and distribution (Barrett et al. 2011). While tundra fires are uncommon in northern Alaska (Racine et al. 2004), recent large fires indicate tundra areas also are vulnerable to rapid changes in vegetation and soil organic carbon (Mack et al. 2011). Slow forest and shrub migration into new areas (Supplemental Material, Fig. 1), altitudinal increases in treeline, and shifts in dominance within plant communities have altered canopy dominance and understory composition (Suarez et al. 1999; Sturm et al. 2001; Myers-Smith et al. 2011). Topographic barriers are important in constraining this expansion (Rupp et al. 2001). River erosion and deposition replace late-successional ecosystems with water and barren fluvial deposits (Nilsson et al. 2013). Lake area has increased through shore erosion and decreased from drainage associated with permafrost degradation (Jones et al. 2011), evaporative loss and paludification (Roach et al. 2011). Storm surges enhanced by sea-ice retreat have led to increased coastal erosion and salinization (Jones et al. 2009). Glacier melting has exposed new barren alpine areas subject to primary succession (Arendt et al. 2009) and affected the geomorphology of glacier-fed river systems (Moore et al. 2009). Increasing human populations and industrial activities also contribute to environmental changes (Walker et al. 1987). Collectively, these drivers contribute to a diverse mosaic of early to late-successional ecosystems where change can occur abruptly through disturbance events (pulses) or gradually through successional processes or chronic stressors (Chapin et al. 2006).

In this study, we used a state-transition modeling approach to project future changes over three 30-year periods for the full range of ecotypes across northwestern Alaska, including the Arctic Network (ARCN) of national parks and the adjacent Selawik National Wildlife Refuge (Supplementary material, Fig. 2). In the first of three models, the baseline time-dependent model allowed us to project future changes as occurring at the same rate as documented by 
large datasets of past changes. The temperature-dependent model assumes that future changes will respond to increasing temperatures, consistent with the common paradigm that climate warming is the root cause of observed arctic change (Hinzman et al. 2005). A third model adjusts the sensitivity (transition rate) of the ecosystems to temperature changes based on perceived positive and negative feedbacks associated with 23 biophysical drivers. While the assumption of linear temperature dependency is simplistic, it provides empirical projections that can be compared to other climate-envelop (Pearson et al. 2013) and dynamic-ecosystem (Euskirchen et al. 2009) models, which also use simplifying assumptions when reducing the complexity of ecological characteristics and drivers. The modeling uses a non-spatial approach to predict changes in areal extent, because the large number of factors and spatial complexity affecting each transition precludes spatial prediction. Specific objectives were to: (1) analyze regional changes in mean annual air temperatures (MAAT); (2) compile data on historical rates of ecosystem change; (3) attribute specific biophysical drivers to each ecological transition; and (4) predict future changes over three 30-year periods (2010-2040, 2040-2070, 20702100) using empirical rates based on time and temperature.

\section{Methods}

\subsection{Air temperature trends}

We analyzed trends in MAAT from nine weather stations near the study area (Barrow, Barter Island, Bettles, Fairbanks, Fort Yukon, Kotzebue, McKinley Park, Nome, and Tanana) using climate data obtained from the Alaska Climate Research Center, University of Alaska Fairbanks (climate.gi.alaska.edu/) and the Western Regional Climate Center (www.wrcc.dri.edu/ summary/Climsmak.html). For each station, we calculated linear regressions of MAAT by year over 1949-2010 or the period of available data, and for periods before ( 1949-1975) and after (1976-2010) the major PDO shift in 1976. From the slope of each regression model we calculated the change in MAAT over a 30 -year period.

Future temperature predictions for the $2010-2040\left(2{ }^{\circ} \mathrm{C}\right), 2040-2070\left(4{ }^{\circ} \mathrm{C}\right)$, and $2070-2100$ $\left(6{ }^{\circ} \mathrm{C}\right)$ periods for northwest Alaska were obtained from the Scenarios Network for Arctic Planning (SNAP, http://www.snap.uaf.edu/datamaps.php) based on midrange (A1B) predictions of greenhouse gas emissions, which assume an aggressive reduction in emissions, as defined by the Intergovernmental Panel on Climate Change. The SNAP modeling selected the five Global Climate Models (GCM) that performed best in Alaska and the Arctic (Walsh et al. 2008). They downscaled the outputs from these models using PRISM data, which accounts for slope, elevation, and proximity to coastlines. The final SNAP products were high-resolution monthly climate data for $\sim 1901-2100$ for Alaska and large regions of Canada. Because projection temperature changes varied by $\sim 1.5^{\circ} \mathrm{C}$ across the study area by 2100 , we used the mid-range value for the region rounded to the nearest whole number for our nonspatial modeling.

\subsection{Observed historical changes and drivers}

Historical change rates, based on documented transitions from one ecotype to another, were compiled from eight published and unpublished studies. Major sources that have comprehensive data sets included data from the ARCN parklands (Swanson 2014, based on change at 7622 locations), Arctic National Wildlife Refuge (unpublished, 3500 locations), Denali National Park (Roth et al. 2007,100 locations), and the Tanana Flats (Jorgenson et al. 2001, 300 locations). These analyses were based on photo-interpretation of old aerial photographs and 
more recent high-resolution satellite imagery or aerial photographs that allowed detailed classification of changes in vegetation structure and composition, as well as geomorphic changes. The ARCN study was based on a systematic grid of points $(20-\mathrm{km}$ spacing $)$ distributed across the 5 parks, while ANWR analysis was based on 35 small grids (each with 100 points, 160-m spacing) randomly distributed across the Refuge, which spans the same mountain range just east of the study area. The Denali Park and Tanana Flats studies also used systematic grids, but covered limited areas. These data points, which were systematically or randomly distributed across large regions rather than high-grading notable areas with high rates of change, were ideal for calculating regional change rates. Other references included data on glaciers (Arendt et al. 2009; Moore et al. 2009; Rabus and Echelmeyer 1998) and waterbodies (Jones et al. 2011). We compiled the data from original sources into a historical-change database using attributes and terminology of the original source and included other information, such as ecoregion, and period of observation.

To allow analysis of data from the different datasets, we cross-walked the ecosystem or vegetation type in the source study to the equivalent ecotype classified by the ARCN mapping (Jorgenson et al. 2009, Supplementary material, Fig. 3). The largest change dataset of Swanson (2014) already used the ARCN ecotypes. Because classification was developed from a quantitative floristic and soils analysis using data from 763 plots sampled across the entire region, the classification was sufficiently detailed to capture the diversity of ecosystems across a broad region. The areal extent of each ecotype was quantified through a supervised classification of Landsat TM satellite imagery (Jorgenson et al. 2009).

A comprehensive set of transitions were developed for each ecotype, as well biophysical factors associated with each transition (for example see Supplementary material, Fig. 4). First, an initial set of all possible transitions was developed from the transitions documented in the data sets. Second, we assigned drivers associated to each change attributed by the author. Third, we then made minor additions to the list of transitions and drivers using information from: (1) scoping workshops for long-term ecological monitoring in Alaska (Martin et al. 2009); and (2) our extensive field experience in the region. Some of these additions involved the inclusion of new ecotypes that occur in warmer regions, but do not currently exist in the region. For example, Upland White Spruce-Herb Forest and Upland Sagebrush Shrub (steppe bluffs) currently occur in warmer boreal regions and have potential to develop in ARCN in the future.

Transition probabilities for each ecotype were developed by: (1) normalizing changes from the varying periods of observations to a standard 30-year period; (2) averaging change rates across studies for each ecotype; and (3) adjusting transition probabilities so that they summed to $100 \%$. The adjustments were necessary because change rates, or transition probabilities, obtained from the various studies frequently had different numbers of transitions for each ecotype (see Supplemental material, Table 2). Values were $2 / 3$ weighted toward ARCN historical data where data allowed, because those data were systematically collected across this same study area. The transition probabilities for an ecotype staying the same were adjusted first, because they were supported by higher numbers of observations. Then, the other transitions from an individual ecotype were normalized so that all transitions summed to $100 \%$. When no data were available for a particular transition from one ecotype to another, we assigned values based on our field experience. These assigned values generally were very small because they were sufficiently rare to have no observations.

\subsection{Modeled ecosystem transitions}

State-transition modeling of future changes for three periods (2010-2040, 2040-2070, and 2070-2100) were calculated in Excel spreadsheets for a time model, temperature model, and a 
rate-adjusted model that adjusted change rates based on perceived climate sensitivity of the driver. The time model, which predicts future changes will occur at the same rate over future 30 -year periods as during the past 30-year period, involved: (1) calculating partial areas resulting from the transition of each ecotype into other ecotypes by multiplying the beginning total area by the transition probabilities; (2) summing the partial areas of the resulting transitions into a new total area for each ecotype for the specific time period; and (3) iteratively calculating changes for each 30-year period based on the total area from the previous period (Supplemental material, Fig. 5).

The temperature model, which projects that future changes with warming will occur at the same rate relative to past temperature changes, involved increasing transition probabilities as a function of the rate of change of temperature. Historical transition rates were calculated as a function of temperature change by dividing the transition rate by the average rate of past temperature change ( $\sim 1949$ to 2010 ) normalized to a 30 -year period $\left(1^{\circ} \mathrm{C} / 30\right.$ years). For future temperature predictions we used the projected temperatures by the Scenarios Network for Arctic Planning (http://www.snap.uaf.edu/datamaps.php) as described above. New transition probabilities for each period were calculated using: adjusted historical 30-year transition probability $\times$ (future temperature increase/past temperature increase)

In the rate-adjusted model, transition probabilities were calculated the same as for the temperature model with the addition of a change-rate factor used to scale changes that are generally believed to be slow to change with temperature (i.e., 0.5 associated with plant migration and plant dominance shifts affected by numerous interacting factors and negative feedbacks) and to changes that have strong positive feedbacks due to interaction with surface water and are therefore highly sensitive to temperature (i.e., 1.5 for glacier melting, and most types of thermokarst). While there is a theoretical justification in the literature for this scaling, no data were available to constrain the values and we view them as working hypotheses. From a practical aspect, this scaling was needed so that some transition probabilities driven by large temperature increases did not exceed $100 \%$ by the end of the three periods.

The amount of change (final area minus beginning area in $\mathrm{km}^{2}$ ) was summarized for each ecotype as both a proportion of the total study area (useful for comparing changes among ecotypes and identifying what is causing the largest overall changes) and as a proportion of initial ecotype area (useful for comparing relative effects among ecotypes) for each time period. These individual ecotype changes were summed to obtain overall cumulative and net changes in area. Cumulative changes across the entire study area were calculated by summing the areas affected by all the partial transitions for every ecotype accumulated over the three periods. Because nearly every ecotype gains area from some transitions and loses area from other transitions, this cumulative sum accounts for all changes, even though some of the changes balance out. Second, net change was calculated as the sum of the change in areas for only those ecotypes gaining area after the end of the three periods. Because the overall gains are matched by an equivalent loss in area (every patch experiences both a gain in some type and a loss in some type), only the gains (absolute values) are summed as the measure of net change (directional shift), with net change being less than cumulative change.

\section{Results}

\subsection{Air temperature trends}

The overall trend in MAAT was $+0.97{ }^{\circ} \mathrm{C}$ per 30 years during the $\sim 1949-2010$ period for the five weather stations nearest the region (Supplementary material, Table 1). Trends for nine 
weather stations that encompass the broader region where historical change rates were determined varied from -0.2 to $1.3{ }^{\circ} \mathrm{C}$ per 30 years. Trends also varied by periods associated with cold and warm phases of the Pacific Decadal Oscillation (Hartmann and Wendler 2005), with predominant cooling trends during 1949-1975 and more mixed trends during 19762010. The overall period, however, which incorporates the large regime shift in 1976, showed strong warming. At Kotzebue, a coastal station nearest the study area, regression analysis indicated that MAAT has increased $1.7^{\circ} \mathrm{C}$ from 1949 to 2010 , for a 30 -year rate of $0.83{ }^{\circ} \mathrm{C}$ (Supplementary material, Fig. 6).

Spatial modeling of temperature distributions by SNAP showed large variability in temperatures across the study area due to topography and ocean proximity, with the baseline average of MAATs for the period 1961-1990 ranging from $-4.8{ }^{\circ} \mathrm{C}$ near the coast to $-13.4{ }^{\circ} \mathrm{C}$ in the highest mountains. By their 2090-2099 period, projected increases in MAAT compared to the baseline varied by 5 to $6.5{ }^{\circ} \mathrm{C}$ across the study area. For our nonspatial modeling purposes, however, we assigned generalized temperature increases of 2,4 , and $6{ }^{\circ} \mathrm{C}$ across the entire study area for the 2010-2040, 20402070, and 2070-2100 periods, respectively.

\subsection{Observed historical changes and drivers}

We compiled a list of 243 potential transitions based on historical rates of ecotype changes documented by 402 observations from 8 studies; 10 transitions were supported by data from 5-6 separate referenced studies, 25 by $3-4$ studies, and 60 by 1-2 studies (see Supplement material, Table 2). We also included 98 potential transitions that we hypothesized to occur based on our field experience. The number of transitions possible for each ecotype ranged from 1 (staying the same as a potential outcome, e.g., Alpine Mafic Barrens) to 11 (e.g., Upland Dwarf Birch-Tussock Shrub). We also attributed each transition to one of 23 geomorphic and ecological drivers likely to be influenced by climate change (Supplement material, Table 2, Fig. 7). Over a century-long period, an area can be affected by multiple transitions over the three periods, for example Upland Dwarf Birch-Tussock Shrub can be replaced by Upland Barrens-Thermokarst (with thermokarst as the driver), then by Upland Alder-Willow Tall Shrub (with early plant succession as the driver), and finally by Upland White Spruce Forest (with late plant succession as the driver).

\subsection{Modeled ecosystem transitions}

The time model, which assumes future transitions occur at the same rate as past transitions, projected a cumulative change (sum of all partial transitions for all ecotypes, or total area undergoing change) of $12.3 \%$ across the region's area $\left(162,868 \mathrm{~km}^{2}\right)$ over the three periods, while overall net change was $6.3 \%$ (sum of all ecotypes gaining area, thus shift to other types) at the end of the three periods,. The cumulative change is larger than the net change because many changes are compensating. For example, the cumulative gains $\left(4053 \mathrm{~km}^{2}\right)$ in Upland White Spruce Forest mainly from post-fire succession and range expansion (partly aided by establishment in thaw slumps) is partially offset by losses $\left(1837 \mathrm{~km}^{2}\right)$ mainly by fire and thermokarst for a net gain of $2216 \mathrm{~km}^{2}$. Thus, cumulative change provides a measure of how dynamic the overall system is, while the net change indicates how these dynamic processes can lead to directional shifts over time. Over the next century, the models project 33 ecotypes gain area, 23 will lose area, and 4 have no change (Fig. 1). Note that during the time period ( $\sim 1950$ 2010) from which the historical transition rates were developed, MAATs increased at a rate of $1{ }^{\circ} \mathrm{C} / 30$ years; at this linear rate, MAATs would be expected to increase by $3{ }^{\circ} \mathrm{C}$ from 2010 to 


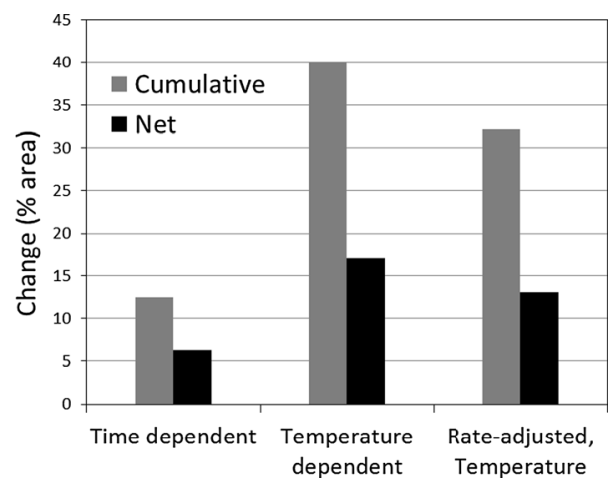

Fig 1 Projected cumulative and net changes in overall area by ecosystem changes from 2010 to 2100 within the ARCN study area

2100. Thus, the time model provides a baseline of the minimum areal changes in ecotypes projected to occur by 2100 .

The temperature model using temperature increases of 2,4 , and $6{ }^{\circ} \mathrm{C}$ for the three periods estimated a cumulative change of $39.9 \%$ and net change of $17.0 \%$. This model provides a high estimate of projected changes by assuming all transitions respond linearly to accelerating warming temperatures with no feedbacks or lags.

The rate-adjusted model, similar to the temperature model but with a change-rate factor, projected a cumulative change of $32.2 \%$ and net change of $13.1 \%$. When comparing periods in the rate-adjusted model, the rate of cumulative change nearly tripled in response to the large increase in temperatures, increasing from $5.8 \%$ during 2010-2040 to $15.7 \%$ during 2070 2100. In this model (Supplemental Information, Table 2) the change-rate factor was adjusted to 0.5 for 87 transitions associated with biophysical drivers that were perceived to have numerous negative feedbacks and time lags (e.g. vegetation change by plant migration or succession), and to 1.5 for 32 transitions with drivers expected to have positive feedbacks (e.g., thermokarst, glacial melting), while 124 transitions had no adjustment (=1). Below, we present the results of the rate-adjusted model, where changes were mostly intermediate between the other two models, to simplify the discussion. We discuss results in terms of changes in: (1) area as a percent of the total study area to highlight changes that affect large areas; (2) relative percent for each ecotype to highlight changes that may affect small areas but may dramatically change the extent of particular ecotypes, with the potential for loss of rare ecotypes; and (3) by driver to identify factors most responsible for the changes. Results from the other two models are presented in Fig. 2.

Ecotypes projected to experience large increases in area as a percent of the total area in the rate-adjusted model (Fig. 2) include Lowland Black Spruce Forest (from forest expansion and post-fire succession), Upland Alder-Willow Tall Shrub (shrub expansion), Lowland Willow Low Shrub (shrub expansion and soil drainage), Upland White Spruce Forest (forest expansion), and Upland Willow Low Shrub (primary succession after thermokarst). Major losses are projected for Lowland Birch-Ericaceous-Willow Low Shrub (post-fire succession and forest expansion), Upland Birch-Ericaceous-Willow Low Shrub (due to thermokarst, fires, and shrub and forest expansion), Upland Dwarf Birch-Tussock Shrub (thermokarst, fires, and shrub and forest expansion), Upland Sedge-Dryas Meadow (thermokarst, shrub expansion, in-situ shrub dominance shifts, and acidification), Lowland Alder Tall Shrub (forest expansion) and 


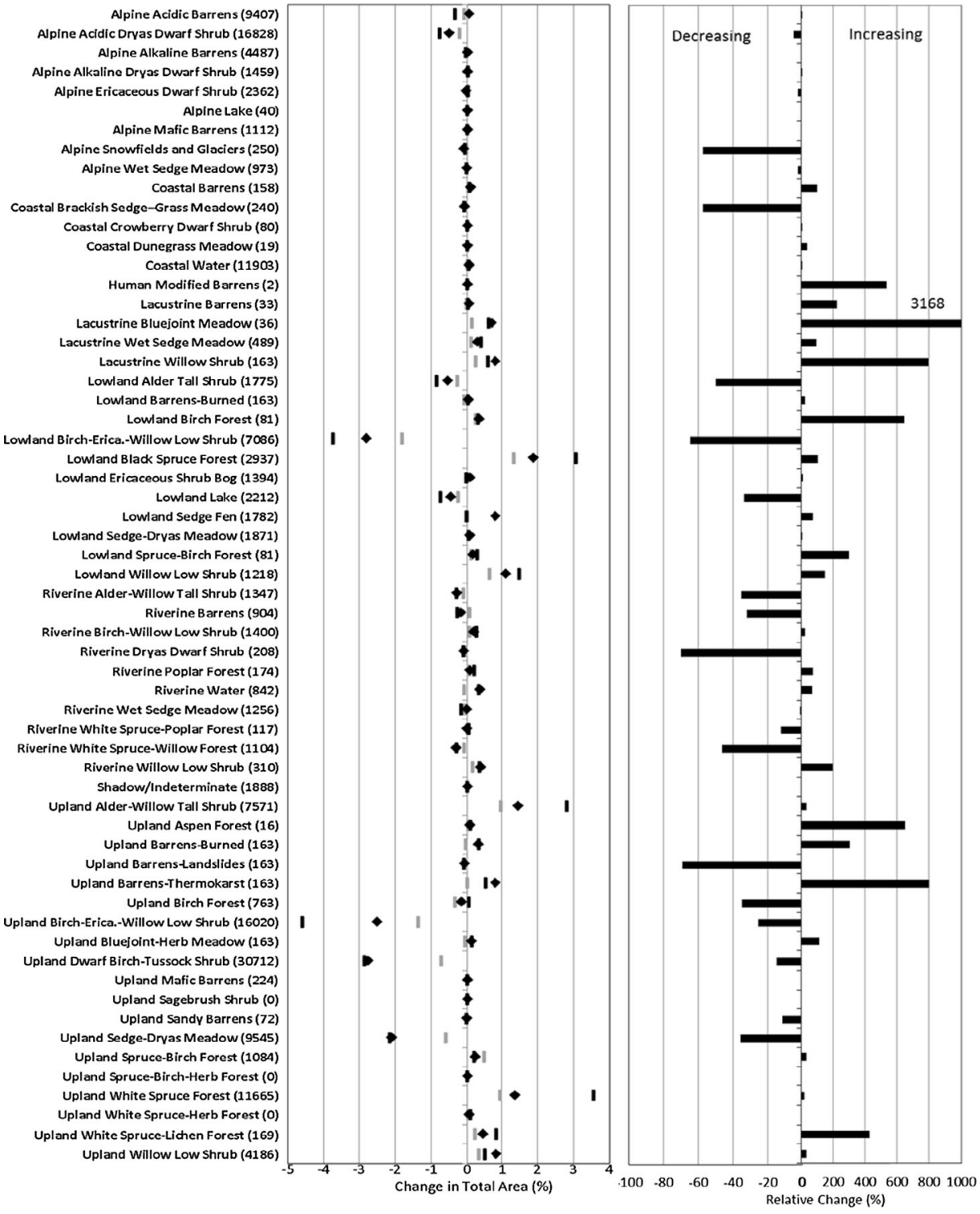

Fig. 2 Projected changes (left) as percent of total study area of ecotypes from 2010 to 2100 based on the time (gray bar), rate-adjusted (diamond), and temperature (black bar) models and (right) as relative change (percent difference from initial area for each ecotype) for the rate-adjusted model. Note different scales on right for decreases and increases. Area $\left(\mathrm{km}^{2}\right)$ in 2010 included with ecotype name

Lowland Lake. Common ecotypes $\left(>1000 \mathrm{~km}^{2}\right)$ that showed little change include Alpine Acidic Barrens, Alpine Acidic Dryas Dwarf Shrub, Alpine Alkaline Barrens, Lowland SedgeDryas Meadow, and Riverine Alder-Willow Tall Shrub.

When grouped by broad physiognomic group (Fig. 3), the rate-adjusted model projects that forests will have the largest gain $(4.1 \%)$ and low shrubs the largest loss $(-4.8 \%)$. Tall shrubs 


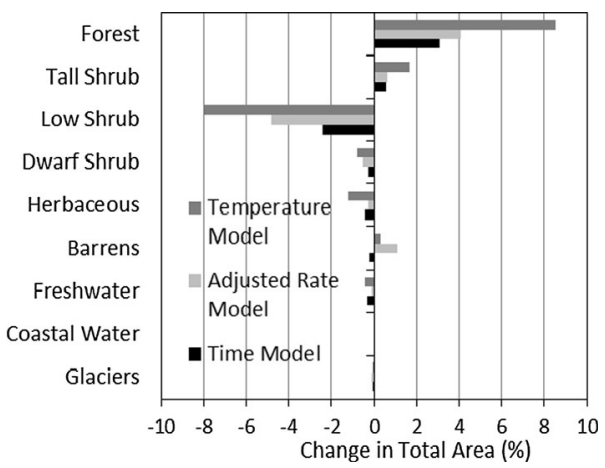

Fig 3 Projected changes in total area for three models aggregated by broad classes

show only a small gain $(0.6 \%)$. Although the model showed fairly large cumulative gains by tall shrubs, the net gain was substantially reduced by the replacement with forest types. Small losses are projected for dwarf shrubs $(-0.5 \%)$ and herbaceous meadows $(-0.2 \%)$. There were large differences among the models, however. The temperature model projected 3 -fold higher gains than the time model for both forests ( 8.5 vs $3.1 \%$ ) and tall shrubs (1.7 vs $0.6 \%)$.

When considering relative changes ( $\%$ of initial area by ecotype), several ecotypes, often covering relatively small areas, had large projected increases by 2100 (Fig. 2), including: Lacustrine Bluejoint Meadow (3168 \% increase, from lake drainage), Lowland Birch Forest (645\%, thermokarst, fires), Human Modified Barrens (532\%, gravel fill, mines), Lacustrine Willow Shrub (794 \%, lake drainage), Upland Aspen Forest (648 \%, warming south-facing

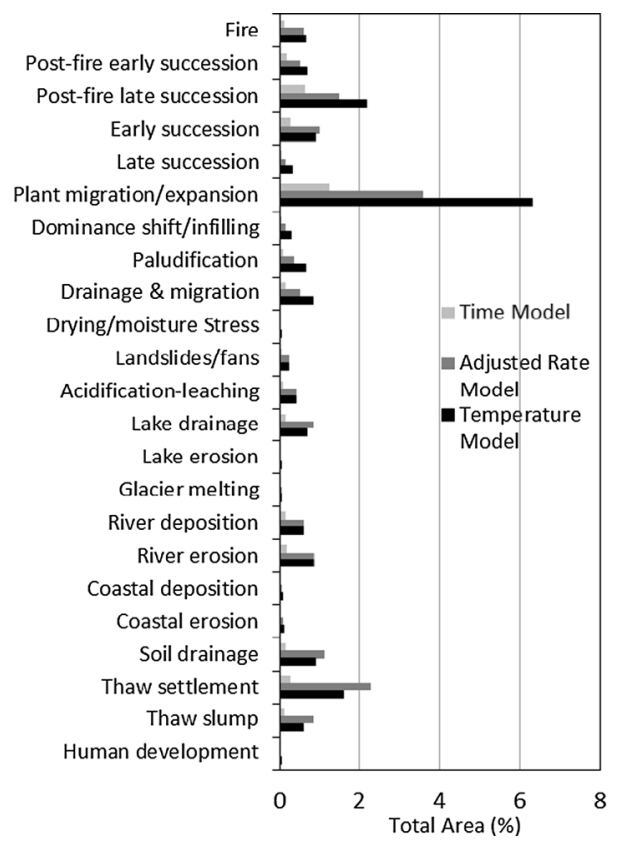

Fig. 4 Changes in cumulative area (\%) during the final 2070-2100 period caused by 23 biophysical 4 drivers used in the three state-transition models 
slopes), Upland Barrens-Thermokarst (801 \%), and Lowland Spruce-Birch Forest (645 \%, late succession). Ecotypes with projected large relative decreases include: Upland BarrensLandslides (-69\%, early succession), Lowland Birch-Ericaceous-Willow Low Shrub (-65\%, post-fire late succession, plant migration), Riverine Dryas Dwarf Shrub (-70\%, shrub expansion), Upland Birch Forest ( $-35 \%$, post-fire late succession to spruce), Coastal Brackish Sedge-Grass Meadow ( $-57 \%$, erosion and sedimentation), Lowland Alder Tall Shrub ( $-50 \%$, forest expansion, succession), and Alpine Snowfields and Glaciers $(-57 \%$, melting).

Biophysical drivers of the ecotype transitions showed large differences in the percent of the total area that they affected (Fig. 4). In all models, most change was driven by drivers involving plant migration into new areas and outward expansion of tall shrubs and trees, post-fire succession, thermokarst (i.e., thaw slumps, detachment slides, thaw lakes, ice-wedge degradation), soil drainage associated with thawing permafrost, and river erosion and deposition. We differentiated the drivers of secondary succession associated with post-fire recovery and primary early and late succession related to colonization of newly exposed mineral surfaces, such as those created by fluvial deposits, thermokarst, and lake drainage. Plant migration/expansion involved shifts of tundra ecotypes (graminoids, dwarf shrub) into tall shrub (alder, tall willow) and forest ecotypes. Dominance shifting/infilling described transitions where preexisting low shrubs increased in height and abundance and overtopped dwarf shrubs and herbaceous plants to transition into low shrub ecotypes. Soil drainage characterized changes where active-layer thickening and permafrost thaw in upland, thaw-stable soils, allows supra-permafrost water to be lowered or drained away. Drainage and migration differentiated transitions where soil drainage simultaneously allowed migration of tall shrubs and trees onto soils that previously were too wet to be suitable. When comparing models during the final 2070-2100 period when MAATs were $6{ }^{\circ} \mathrm{C}$ warmer, the changes for many of the drivers in the temperature model were 3-9 fold higher than for the time model.

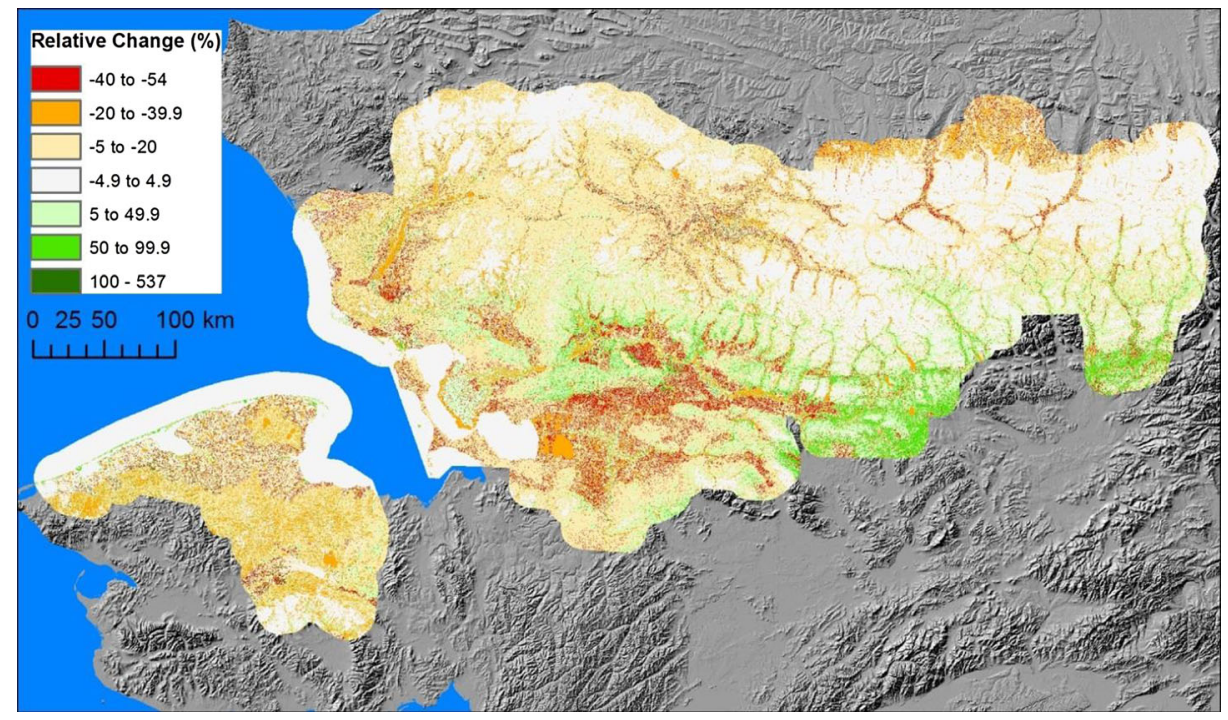

Fig. 5 Map of vulnerability of ecosystems to changes from 2010 to 2100 from climate warming. Map 2 shows current distribution of ecotypes predicted to increase or decrease in extent 
The current distribution of ecotypes that are projected to undergo large relative increases or decreases is presented in Fig. 5. It should be noted, however, that we could not identify specifically where these transitions will occur because locations of future disturbances (e.g., fire, thermokarst) are unpredictable and so these models are not spatially explicit. The map indicates that large decreases will occur in lowland ecotypes in the southern Brooks Range associated with fires, thermokarst, and succession, and that the forest and tall shrub ecotypes along the southern Brooks Range will be the source of moderate increases in those ecotypes in the future. In contrast, few changes are predicted for the high mountains of the Brooks Range.

\section{Discussion}

The state-transition models indicate that arctic and boreal regions have diverse and dynamic ecosystems subject to change from a large number of biophysical drivers. The strength of this approach was the use of comprehensive datasets of past changes at more than 11,000 locations to provide an empirical basis for projecting future change. The approach also deals with a wide diversity of ecotypes and the effects from a large variety of biophysical drivers that include many disturbance mechanisms. Disturbances associated with fire and thermokarst, and to a lesser extent channel dynamics, are particularly strong factors controlling change. Finally, the approach highlights the dynamics of iterative changes among ecosystems that result in substantial cumulative changes, while the overall net gains and losses were relatively modest. The main weakness of the transition models is the simplistic use of empirical historical transition rates that ignore dynamic biogeochemical processes that control growth and competitive interactions. To overcome this simplicity, however, would require separate dynamic models and parameterization for every ecotype and driver.

Overall, the projected net changes from all models were relatively modest, ranging from $6 \%$ in the time model to $17 \%$ in the temperature model, consistent with the small changes evident in repeat photographs spanning nearly a century (Supplementary material, Fig. 1). The time model provides a strongly supported baseline for comparing the temperature model, as well as models from other studies. We consider the temperature model to overestimate changes, because it is unlikely that vegetation changes will respond linearly to the projected large temperature increases, given the numerous biological feedbacks and life history characteristics that affect dispersal, establishment, growth, competitive interactions, and nutrient cycling. We consider the intermediate results from the rate-adjusted model to be the most likely outcome, although we recognize the lack of quantitative support for the simple rate adjustments.

In comparison to other modeling approaches, our empirical state-transition models indicate that ecosystem changes ( $13 \%$ net change for the rate-adjusted model) are substantially slower than reported by other studies. Pearson et al. (2013) used a climate-envelop type model to project that vegetation in $48-69 \%$ of the circumarctic region will shift to a different class by the 2050s under scenarios of climate change and restricted tree dispersal. Climate-envelop modeling by SNAP (2012) projected that ecosystem types (cliomes) in northwest Alaska would experience large shifts in forest types but didn't quantify changes by regions. Euskirchen et al. (2009) developed a terrestrial ecosystem model that showed large changes in relative abundance of plant function types and productivity for sedge tundra, shrub tundra, and forest, but basic vegetation types did not change. Wolf et al. (2008) developed a dynamic vegetation model that showed expansion of forests, decreased shrublands, and northward shifts of tundra in response to climate warming in the Barents Region, but did not incorporate disturbance processes. 
Several key sources of uncertainty remain in our models. First, errors in the classification of ecotypes occur in the change-detection interpretation conducted by the source studies and in development of the ecotype map for the study area. Second, while transition probabilities for the common ecotypes were supported by a large data set from change-detection studies, probabilities for uncommon types frequently were based on expert knowledge. The uncommon types, however, accounted for only a very small percentage of the area and thus had little effect on overall model results; the lack of data is primarily a concern for projections of relative changes because of the small denominator in the calculations. Third, we were not able to include several important drivers, such as herbivory effects on species composition and snow depth on ecological processes, because there was a lack of data of sufficient temporal length or across the range of ecotypes to quantify transition probabilities associated with these factors. Fourth, we recognized that shifts in precipitation patterns may influence ecotype transitions, but there is substantial uncertainty in precipitation predictions, and the spatial and temporal distribution of the historical change and climatic data were insufficient to evaluate multifactor effects on change rates and future transition probabilities. Fifth, the temperature model depends on rates of change and not on the absolute temperature. This can be a limitation for some transitions when temperatures meet a threshold, such as $0{ }^{\circ} \mathrm{C}$ for ice melting associated with thermokarst, or if the processes are non-linear. However, many process-based models include biogeochemical functions whose rates are sensitive to temperature increases without radical thresholds, so that our temperature model is similar in some respects to those models in that transition rates increase with temperature. In the rate-adjusted model we indirectly addressed the problem through the use of a change-rate factor that increases the temperature sensitivity for thawing-related processes.

Feedbacks and response lags are poorly understood and their effects are a common problem with models predicting future responses to climate change. In our rate-adjusted model, where we adjusted the change-rate factor used in the transition probabilities to increase or decrease the effect of temperature associated with each driver; changes were moderately sensitive to the adjustments. When compared with the temperature model (change-rate factor $=1$ for all transitions), the overall net change was $17 \%$ compared to $13.1 \%$ for the rate-adjusted model. For some ecotypes, however, the differences were considerable (Fig. 2), such as for Lowland Birch-EricaceousWillow Low Shrub, Lowland Black Spruce Forest, and Upland Alder-Willow Tall Shrub. Changes in these ecotypes tended to be more driven by fire, secondary succession, and plantmigration, where the change-rate factor was adjusted to 0.5 for the perceived negative feedbacks that slow the response to future temperature changes. While we used a simplistic approach to account for positive and negative feedbacks, it highlights the need for better data on the physical and biological feedbacks that vary in nature and importance across diverse ecosystems.

It is important to note that ecotypes, in themselves, do not respond to the environment, but are comprised of assemblages of species that respond individually to stressors and environmental change (Huntley 1991). Using the ecosystem level of organization, which identifies changes in the dominant species that are used to characterize the ecotypes, is useful, however, because changes in dominant species also can represent changes in associated understory species. Furthermore, large changes in environmental conditions, such as from lake to barren drained-lake basin, can cause wholesale shifts in closely-associated plant assemblages.

Projected changes of ecotypes in the study area are likely to have regional to global consequences related to climate feedbacks, thermokarst, trophic-level interactions, and biodiversity. Many of the ecosystem types that were abundant in our study area are similar to those in the circumpolar region (Walker et al. 2005), and the main drivers of change, such as thermokarst (Grosse et al. 2011), fire (Barrett et al. 2011), shrub expansion (Myers-Smith et al. 2012), and lake drainage (Smith et al. 2005) also are common in the Russian and Canadian 
north. Thus, the types of shifts in vegetation in northwest Alaska are likely to be widespread with their accompanying effects on albedo, evapotranspiration, and biomass across the broader circumpolar region and provide feedbacks to the global system (Chapin et al. 2006; Euskirchen et al. 2009; Rocha et al. 2012; SNAP 2012; Pearson et al. 2013). The release of carbon dioxide and methane from decomposition of soil carbon from thawing permafrost (Grosse et al. 2011) is of particular concern to the global climate system. The projected temperature increase over the next century will bring regional MAATs from the existing $-6{ }^{\circ} \mathrm{C}$ range to near $0{ }^{\circ} \mathrm{C}$ in the region and approach a threshold where thermokarst processes will accelerate. The relatively large gains or losses in various ecotypes that are important to individual wildlife species could have large impacts on some species, and the trophic-level interactions among plants, herbivores, and predators (Joly et al. 2009; Marcot et al., under review). With changes accelerating, we are concerned that longer-term changes after 2100 will lead to large decreases in some ecotypes that could have substantial effects on biodiversity.

\section{Conclusions}

The state-transition models indicate that arctic and boreal regions have diverse and dynamic ecosystems subject to changes from a large number of biophysical drivers, which provide an enormous challenge for assessing the impacts of climate change. The models, and the historical rates of change upon which they were based, show these ecosystems constantly undergo change at widely varying rates, and that climate warming will increase the rates of change, particularly those associated with shrub and forest expansion, permafrost degradation, and fire. Yet, the models project net changes will be relatively modest over the 90 -yr period, ranging from $6 \%$ for the time model to $17 \%$ for the temperature model. Cumulative changes, which sum the losses and gains of all ecotypes over the three periods, ranged from $12 \%$ for the time model to $40 \%$ for the temperature model. While the overall system is highly dynamic, many of the changes are offsetting, thus leading to smaller shifts in overall regional composition. The projected increase in MAAT of $6{ }^{\circ} \mathrm{C}$ by 2100 , however, is huge relative to historical changes and lead to changes accelerating toward the end of the century. This state-transition modeling is unique in that it provides a comprehensive assessment of likely future changes from a large number of drivers affecting the full diversity of ecosystems across a broad region.

Acknowledgments This project was funded by the U.S. Geological Survey, with in-kind support from the National Park Service, Fish and Wildlife Service, and USDA Forest Serve. We appreciate the input of Robert Winfree, Carl Roland, Leslie Holland-Bartels, Carl Markon, Terry Chapin, and one anonymous reviewer.

Open Access This article is distributed under the terms of the Creative Commons Attribution License which permits any use, distribution, and reproduction in any medium, provided the original author(s) and the source are credited.

\section{References}

Arendt A, Walsh J, Harrison W (2009) Changes of glaciers and climate in northwestern north America during the late twentieth century. J Clim 22:4117-4134

Barrett K, McGuire AD, Hoy EE, Kasischke E (2011) Potential shifts in dominant forest cover in interior Alaska driven by variations in fire severity. Ecol Appl 21:2380-2396 
Chapin FS III, Oswood MW, Van Cleve K, Viereck LA, Verbyla DL (2006) Alaska's changing boreal forest. Oxford Univ Press, New York

Euskirchen ES, McGuire AD, Chapin FS III, Li SY, Thompson CC (2009) Changes in vegetation in northern Alaska under scenarios of climate change, 2003-2100: implications for climate feedbacks. Ecol Appl 19: 1022-1043

Grosse G, Romanovsky V, Jorgenson T, Anthony KW, Brown J (2011) Vulnerability and feedbacks of permafrost to climate change. Eos Trans AGU 92:73-80

Hartmann B, Wendler G (2005) The significance of the 1976 pacific climate shift in the climatology of Alaska. J Clim 18:4824 4839

Hinzman L, Bettez N, Bolton B et al (2005) Evidence and implications of recent climate change in terrestrial regions of the Arctic. Clim Chang 72:251-298

Huntley B (1991) How plants respond to climate change: migration rates, individualism and the consequences for plant communities. Ann Bot 67:15-22

Joly K, Jandt RR, Klein DR (2009) Decrease of lichens in Arctic ecosystems: the role of wildfire, caribou, reindeer, competition and climate in north-western Alaska. Pol Res 28(20):433-442

Jones BM, Arp CD, Jorgenson MT et al (2009) Increase in the rate and uniformity of coastline erosion in Arctic Alaska. Geophys Res Lett 36, L03503

Jones BM, Grosse GD AC, Jones MC, Walter Anthony KM, Romanovsky VE (2011) Modern thermokarst lake dynamics in the continuous permafrost zone, northern Seward Peninsula, Alaska. J Geophys Res - Biogeosci 116:G00M03

Jorgenson MT, Racine CH, Walters JC, Osterkamp TE (2001) Permafrost degradation and ecological changes associated with a warming climate in central Alaska. Clim Chang 31(48):551-579

Jorgenson MT, Shur YL, Pullman ER (2006) Abrupt increase in permafrost degradation in Arctic Alaska. Geophys Res Lett 33:L02503, 02510.01029/02005GL024960

Jorgenson MT, Roth JE, Miller PF et al (2009) An ecological land survey and landcover map of the arctic network. National Park Service, Ft Collins, CO, p 307

Jorgenson MT, Harden J, Kanevskiy M, 8 others (2013) Reorganization of vegetation, hydrology and soil carbon after permafrost degradation across heterogeneous boreal landscapes. Env Res Lett 8:035017. 035013p

Mack MC, Verbyla DL, Bret-Harte MS et al (2011) Carbon loss from an unprecedented Arctic tundra wildfire. Nature 475:489-492

Marcot BG, Jorgenson MT, Lawler JP, Handel CM, DeGange AR (Under review) Projected changes in wildlife habitats in Arctic natural areas of northwest Alaska. Clim Change

Martin PD, Jenkins JL, Adams FJ et al (2009) Wildlife responses to environmental Arctic change. U.S. Fish and Wild Serv, Fairbanks, AK, p 138

Moore RD, Fleming SW, Menounos B et al (2009) Glacier change in western North America: influences on hydrology, geomorphic hazards and water quality. Hydrol Process 44(23):42-61

Myers-Smith IH, Forbes BC, Wilmking M, Hallinger M, Lantz TC (2011) Shrub expansion in tundra ecosystems: dynamics, impacts and research priorities. Envir Res Lett 6:045509

Nilsson C, Jansson R, Kuglerová L, Lind L, Ström L (2013) Boreal riparian vegetation under climate change. Ecosystems 16:401-410

Pearson RG, Phillips SJ, Loranty MM et al (2013) Shifts in Arctic vegetation and associated feedbacks under climate change. Nat Clim Chang 3:673-677

Potter C, Li S, Crabtree R (2013) Changes in Alaskan tundra ecosystems estimated from MODIS Greenness Trends, 2000 to 2010. J Geophys Rem Sens 2:6

Rabus BT, Echelmeyer KA (1998) The mass balance of McCall Glacier, Brooks Range, Alaska, U.S.A.; its regional relevance and implications for climate change in the Arctic. J Glac 55 44:333-351

Racine C, Jandt R, Meyers C, Dennis J (2004) Tundra fire and vegetation change along a hillslope on the Seward Peninsula, Alaska, U.S.A. Arct Antarct Alp Res 36:1-10

Riordan B, Verbyla D, McGuire AD (2006) Shrinking ponds in subarctic Alaska based on 1950-2002 remotely sensed images. J Geophys Res 111:G04002

Roach J, Griffith B, Verbyla D, Jones J (2011) Mechanisms influencing changes in lake area in the Alaskan boreal forest. Glob Chang Biol 17:2567-2583

Rocha AV, Loranty MM, Higuera PE, and 7 others (2012) The footprint of Alaskan tundra fires 61 during the past half-century: implications for surface properties and radiative forcing. Env Res Lett 7:(8 p.)

Roth JE, Jorgenson MT, Macander MJ, Dissing D (2007) Evaluation of remote sensing techniques for monitoring landscape change in Denali National Park. Prepared for National Park Service, Fairbanks, AK by ABR, Inc., Fairbanks, AK, Fairbanks, AK, p. 48

Rupp TS, Chapin FSI, Starfield AM (2001) Modeling the influence of topographic barriers on treeline advance at the forest-tundra ecotone in northwestern Alaska. Clim Chang 48(399-68):416

Smith LC, Sheng Y, MacDonald GM, Hinzman LD (2005) Disappearing arctic lakes. Science 308:1429 